\title{
Low-stringency single specific primer PCR for identification of Leptospira
}

\author{
Correspondence \\ Matilde Cota Koury \\ kourymat@mono.icb.ufmg.br
}

Received 22 March 2002

Accepted 23 October 2002

\author{
Marluce A. Assunção Oliveira, ${ }^{1}$ Otávia L. Caballero, ${ }^{4}$ Annamaria R. Vago, ${ }^{2}$ \\ Rudy A. Harskeerl, ${ }^{5}$ Álvaro J. Romanha, ${ }^{6}$ Sérgio D. J. Pena, ${ }^{3}$ \\ Andrew J. G. Simpson ${ }^{4}$ and Matilde Cota Koury ${ }^{1}$
}

${ }^{1-3}$ Departamento de Microbiologia ${ }^{1}$, Departamento de Morfologia ${ }^{2}$ and Departamento de Bioquímica e Imunologia ${ }^{3}$, Instituto de Ciências Biológicas, Universidade Federal de Minas Gerais, Av. Antônio Carlos, 6627, CP 486, CEP: 31270-901, Belo Horizonte, Minas Gerais, Brazil

${ }^{4}$ Laboratory of Cancer Genetics, Ludwig Institute for Cancer Research, São Paulo, Brazil

${ }^{5}$ Department of Biomedical Research, Royal Tropical Institute, Amsterdam, The Netherlands

${ }^{6}$ Centro de Pesquisas 'René Rachou' - FIOCRUZ, Belo Horizonte, Minas Gerais, Brazil

\begin{abstract}
Thirty-five Leptospira serovars from the species Leptospira interrogans, Leptospira borgpetersenii, Leptospira santarosai, Leptospira kirschneri, Leptospira weilii, Leptospira biflexa and Leptospira meyeri were characterized by the low-stringency single specific primer PCR (LSSP-PCR) technique. LSSP-PCR analysis was performed to detect DNA polymorphisms in a 285 bp DNA fragment amplified from genomic DNA with G1 and G2 selected primers. Similar LSSP-PCR profiles were obtained for serovars from the same genomic species, while serovars from non-related species produced distinct multiband patterns. Based on the data from sequence analysis, all genomic fragments amplified with G1 and G2 primers from distinct serovars of Leptospira were $285 \mathrm{bp}$ in length, with nucleotide variation observed most frequently among different genomic species. The simplicity and accuracy of the LSSP-PCR technique were found to be suitable for identification of Leptospira species.
\end{abstract}

\section{INTRODUCTION}

Leptospirosis is an ubiquitous zoonotic infection. The genus Leptospira is classified in 13 genomic species based upon DNA relatedness: Leptospira interrogans sensu stricto, Leptospira borgpetersenii, Leptospira inadai, Leptospira noguchi, Leptospira santarosai, Leptospira weilii, Leptospira biflexa sensu stricto, Leptospira meyeri, Leptospira wolbachii, Leptospira parva, Leptospira kirschneri, Leptospira alexanderi and Leptospira fainei (Yasuda et al., 1987). The precise identification and classification of leptospires is important for epidemiological and public health surveillance.

LSSP-PCR (low-stringency single specific primer PCR) is a rapid and simple technique that detects sequence variations in DNA fragments by amplification under very low-stringency conditions with a single primer specific for one of the extremities of the template (Pena et al., 1994).

Molecular diagnostic methods are increasingly being used

Abbreviation: LSSP-PCR, low-stringency single specific primer-PCR.

An alignment of the sequences of $P C R$ products obtained with primers $G 1$ and $\mathrm{G} 2$ is available as supplementary material in JMM Online (http:// jmm.sgmjournals.org/). for clinical diagnosis in endemic areas because of their sensitivity and specificity. PCR amplification techniques should help to characterize any Leptospira DNA sequences present. Especially in the early stage of an outbreak, it can be extremely valuable to characterize further any diagnostic DNA sequences that have been amplified in order to confirm the amplification as being definitively derived from Leptospira and not due to an anomalous amplification. This can be done by hybridization, restriction endonuclease digestion or DNA sequencing. Each of these approaches, however, requires the use of additional reagents and equipment and thus adds to the complexity of the diagnostic process.

In this context, LSSP-PCR represents an important alternative in that it involves a simple repetition of the PCR process with one of the two primers used in the initial amplifications, but it is highly sensitive to the sequence content of the gene fragment being analysed. Furthermore, variations in the sequence of the amplified product can assist in the precise identification of the infecting organism to the species and serovar levels. This is of critical value in the epidemiological assessment of an outbreak and in attempts to identify potential sources of exposure.

We have shown previously that preliminary Leptospira 
identification could be achieved on the basis of the apparent mobility of PCR products generated for Leptospira in polyacrylamide gels (Oliveira et al., 1995). We have also demonstrated that reamplification of the same products by LSSP-PCR could be used to identify some Leptospira species (Oliveira et al., 1994).

In this work, we have extended our initial study and performed LSSP-PCR for genetic characterization of 35 serovars belonging to seven genomic species of Leptospira. Specific banding profiles were obtained for serovars originating from the same genomic species. Thus, LSSP-PCR represents a new, sensitive and efficient tool for the molecular typing of serovars of Leptospira.

\section{METHODS}

Leptospira serovars. Thirty-five Leptospira serovars from the species L. interrogans, L. borgpetersenii, L. santarosai, L. kirschneri, L. weilii, $L$. biflexa and L. meyeri were included in this study (Table 1). The Leptospira serovars were cultured in a liquid medium of Ellinghausen and McCullough, as modified by Johnson \& Harris (1967) (EMJH medium), under aerobic conditions at $28^{\circ} \mathrm{C}$ in the absence of light.

DNA isolation. Approximately $10^{6}-10^{8}$ cells from $1 \mathrm{ml}$ of a 7 -day culture were collected by centrifugation at $13000 \mathrm{~g}$ prior to DNA preparation. Subsequently, cells were incubated overnight at $50{ }^{\circ} \mathrm{C}$ with $200 \mu \mathrm{l}$ lysis buffer [50 mM Tris/HCl, pH 8.0; 50 mM EDTA; $100 \mathrm{mM}$ $\mathrm{NaCl} ; 1 \%(\mathrm{w} / \mathrm{v}) \mathrm{SDS}$ ] containing $100 \mu \mathrm{g}$ proteinase $\mathrm{K} \mathrm{ml}^{-1}$. DNA was extracted with phenol/chloroform and precipitated with ethanol (Tamai et al., 1988).

LSSP-PCR. The LSSP-PCR technique is a two-step procedure: the first step utilizes two primers to obtain PCR products, which are then used as templates in a second step of amplification using low-stringency conditions and a single primer.

Specific PCR was undertaken with the primers G1 (5'-CTG AATCGCTGTATAAAAGT-3') and G2 (5'-GGAAAACAAATGGT CGGAAG-3'), derived from sequences obtained from a genomic library of L. interrogans serovar icterohaemorrhagiae strain RGA, which were described previously (Gravekamp et al., 1993). There was no crossreaction of the G1 and G2 primers when used with several other spirochaetes (i.e. Borrelia burgdorferi and Treponema reiteri), various other micro-organisms such as Mycobacterium spp., Klebsiella pneumoniae, Streptococcus pneumoniae, Salmonella spp., Neisseria gonorrhoeae, Pseudomonas aeruginosa, Yersinia enterocolitica and Escherichia coli, or human DNA (Gravekamp et al., 1991). Amplification was carried out in a volume of $10 \mu$ l containing $5 \mathrm{ng}$ genomic DNA, $1.5 \mathrm{mM} \mathrm{MgCl}_{2}, 200$ $\mu \mathrm{M}$ each of the four dNTPs, $0 \cdot 4$ IU Taq DNA polymerase (Cenbiot) and $1 \mathrm{pmol}$ of each primer in $10 \mathrm{mM}$ Tris/ $\mathrm{HCl}, \mathrm{pH} 8 \cdot 0,50 \mathrm{mM} \mathrm{KCl}$, under $20 \mu \mathrm{l}$ mineral oil. After an initial denaturation step of $94^{\circ} \mathrm{C}$ for $3 \mathrm{~min}$, the specific PCR program consisted of 30 cycles of $94{ }^{\circ} \mathrm{C}$ for $30 \mathrm{~s}, 51^{\circ} \mathrm{C}$ for $1 \mathrm{~min}$ and $72{ }^{\circ} \mathrm{C}$ for $1 \mathrm{~min}$. The last cycle consisted of an extension step at $72{ }^{\circ} \mathrm{C}$ for $3 \mathrm{~min}$.

Products obtained from the PCR step were run on a $1.5 \%$ ethidiumbromide-stained agarose gel, excised from the gel by aspiration and added to Eppendorf tubes containing $50 \mu \mathrm{l}$ double-distilled sterile water. After heating at $95^{\circ} \mathrm{C}$ to melt the agarose, $1 \mu$ of eluate was taken as the template for the LSSP-PCR.

LSSP-PCR was also carried out under $20 \mu \mathrm{l}$ mineral oil in a volume of $10 \mu \mathrm{l}$ containing $1 \mu \mathrm{l}$ DNA template, $1.5 \mathrm{mM} \mathrm{MgCl}_{2}, 200 \mu \mathrm{M}$ each of the four dNTPs, 1.6 IU Taq DNA polymerase (Cenbiot) and 48 pmol of primer G1 or G2 in $10 \mathrm{mM}$ Tris/ $\mathrm{HCl}, \mathrm{pH} 8 \cdot 0,50 \mathrm{mM} \mathrm{KCl}$. After a denaturation step at $94{ }^{\circ} \mathrm{C}$ for $6 \mathrm{~min}$, the LSSP-PCR program consisted of 35 cycles of $94^{\circ} \mathrm{C}$ for $1 \mathrm{~min}$ and $30{ }^{\circ} \mathrm{C}$ for $1 \mathrm{~min}$ (Pena et al., 1994). Five microlitres of LSSP-PCR products were analysed by electrophoresis on $8 \%(\mathrm{w} / \mathrm{v})$ polyacrylamide gels followed by silver staining (Sanguinetti et al., 1994).

Sequencing of PCR products. DNA sequencing was performed on PCR products obtained by amplification with G1 and G2 primers from genomic DNA of eight serovars from four distinct genomic species of Leptospira: L. interrogans (serovars icterohaemorrhagiae, australis and hardjo), L. borgpetersenii (serovars hardjobovis and ballum), L. weilii (serovars celledoni and coxi) and L. meyeri (serovar ranarum). For cloning and sequencing procedures, kits supplied by Applied Biosystems were used according to the manufacturer's instructions. Nucleotide sequences were determined in an Automated DNA sequencer (Applied Biosystems) and analysed with the PC Gene software (release 6.6; Genofit).

\section{RESULTS}

\section{LSSP-PCR analysis}

A $285 \mathrm{bp}$ fragment was specifically amplified from all serovars of Leptospira used in this study (Table 1) by PCR with the primers G1 and G2. This fragment was further characterized using LSSP-PCR with primer G1 or G2.

In order to determine the capacity of LSSP-PCR to detect possible polymorphisms present in the target fragment of $285 \mathrm{bp}$, we initially used primer G2 for analysis of the PCR products originating from different genomic species of the genus Leptospira (Fig. 1). Distinct and informative profiles presenting multiple bands were obtained for four serovars belonging to $L$. interrogans, $L$. borgpetersenii, L. biflexa and $L$. weilii. Genetic signatures obtained from Leptospira with primer G2 were made up of fragments ranging from 100 to $1400 \mathrm{bp}$, with some larger than the $285 \mathrm{bp}$ PCR products used as template for the LSSP-PCR.

We subsequently used the LSSP-PCR technique to analyse different serovars from the same genomic species (L. interrogans), with the goal of determining the usefulness of genetic signatures in the identification of serovars belonging to the same genomic species.

Fig. 2 shows LSSP-PCR profiles obtained through the analysis of 19 serovars from the genomic species L. interrogans with the primer G1. Very similar genetic signatures were obtained for all serovars analysed, which were mainly composed of three fragments (Table 2). Serovars canicola, pomona and hebdomadis presented an additional band of approximately 267 bp (Fig. 2, arrows; Table 2).

Gene signatures obtained through the analysis of 13 serovars belonging to the genomic species $L$. interrogans with the primer G2 are shown in Fig. 3. The main constitutive fragments of LSSP-PCR profiles are listed in Table 2. More complex, informative and identical profiles were obtained for each of the serovars analysed, with no distinction between the profiles obtained for the serovars canicola, pomona and hebdomadis.

In order to evaluate the potential usefulness of genetic 
Table 1. Leptospira strains used in this study

The sizes of PCR products reflect their electrophoretic mobility (in bp) relative to DNA size standards; all products were shown by DNA sequencing to be $285 \mathrm{bp}$ long.

\begin{tabular}{|c|c|c|c|}
\hline Strain & Serogroup* & Serovar & $\begin{array}{c}\text { PCR } \\
\text { product } \\
(\text { bp) }\end{array}$ \\
\hline \multicolumn{4}{|l|}{ L. interrogans } \\
\hline Ballico $\dagger$ & Australis $^{a, b, c}$ & australis & 295 \\
\hline Akiyami A & Autumnalis ${ }^{a, b}$ & autumnalis & 295 \\
\hline Swart & Bataviae $^{c}$ & bataviae & 295 \\
\hline Van Tienen & Bataviae $^{a, b, c}$ & bataviae & 295 \\
\hline Hond Utrecht IV & Canicola $^{a, b}$ & canicola & 295 \\
\hline Sentot & $\operatorname{Djasiman}^{a, b}$ & sentot & 295 \\
\hline Wijnberg & Icterohaemorrhagiae $^{c}$ & copenhageni & 295 \\
\hline M 20 & Icterohaemorrhagiae $^{a}$ & copenhageni & 295 \\
\hline $\mathrm{RGA}^{\mathrm{T}} \dagger$ & Icterohaemorrhagiae $^{a, b, c}$ & icterohaemorrhagiae & 295 \\
\hline Naam & Icterohaemorrhagiae $^{a}$ & naam & 295 \\
\hline Pomona & Pomona $^{a, b}$ & pomona & 295 \\
\hline Salinem & Pyrogenes $^{a, b}$ & pyrogenes & 295 \\
\hline Hardjoprajtino & Sejroe ${ }^{a, c}$ & hardjo & 295 \\
\hline Hebdomadis & Hebdomadis $^{a}$ & hebdomadis & 295 \\
\hline Lai & Icterohaemorrhagiae $^{c}$ & lai & 295 \\
\hline Sumner & Canicola $^{a}$ & sumneri & 295 \\
\hline Vleermnis & Canicola $^{a}$ & shueffneri & 295 \\
\hline Jalna & Australis $^{c}$ & jalna & 295 \\
\hline BD 92 & Australis $^{c}$ & bangkok & 295 \\
\hline Muenchen C 90 & Australis $^{c}$ & muenchen & 295 \\
\hline Lora & Australis $^{c}$ & lora & 295 \\
\hline \multicolumn{4}{|l|}{ L. borgpetersenii } \\
\hline Castellon 3 & Ballum $^{a, b, c}$ & castellonis & 260 \\
\hline Veldrat Bataviae $46^{\mathrm{T}}$ & Javanica $^{a, b}$ & javanica & 255 \\
\hline Mus $127 \dagger$ & Ballum $^{c}$ & ballum & 270 \\
\hline Lely $607 \dagger$ & Sejroe & hardjobovis & 270 \\
\hline \multicolumn{4}{|l|}{ L. santarosai } \\
\hline LT $821^{\mathrm{T}}$ & Shermani $^{a, b}$ & shermani & 255 \\
\hline CZ 390 & $\operatorname{Sarmin}^{c}$ & weaveri & 280 \\
\hline TRVL 112499 & Pyrogenes $^{c}$ & princestown & 270 \\
\hline LT 117 & $\operatorname{Mini}^{c}$ & georgia & 270 \\
\hline \multicolumn{4}{|l|}{ L. kirschneri } \\
\hline Ndahambukuje & Icterohaemorrhagiae $^{a}$ & ndahambukuje & 280 \\
\hline Moskva V & Grippotyphosa & grippotyphosa & 280 \\
\hline \multicolumn{4}{|l|}{ L. weilii } \\
\hline Celledoni ${ }^{\mathrm{T}} \dagger$ & Celledoni $^{c}$ & celledoni & 260 \\
\hline Coxi $\dagger$ & Javanica $^{c}$ & $\operatorname{coxi}$ & 260 \\
\hline \multicolumn{4}{|l|}{ L. biflexa } \\
\hline $\mathrm{CH} 11$ & Andamana $^{a}$ & andamana & 270 \\
\hline Patoc $\mathrm{I}^{\mathrm{T}}$ & Semaranga ${ }^{a}$ & patoc & 270 \\
\hline \multicolumn{4}{|l|}{ L. meyeri } \\
\hline Iowa City Frog ${ }^{\mathrm{T}}\left(\mathrm{ICF}^{\mathrm{T}}\right) \dagger$ & Ranarum $^{c}$ & ranarum & 270 \\
\hline Veldrat Sem 173 & Semaranga ${ }^{c}$ & semaranga & 270 \\
\hline
\end{tabular}

* Serovars obtained from: $a$, Instituto Adolfo Lutz, São Paulo, Brazil; b, Laboratório de Leptospirose, FIOCRUZ, Rio de Janeiro, Brazil; $c$, Royal Tropical Institute, Amsterdam, The Netherlands.

$\uparrow$ Strain used for DNA sequencing. 


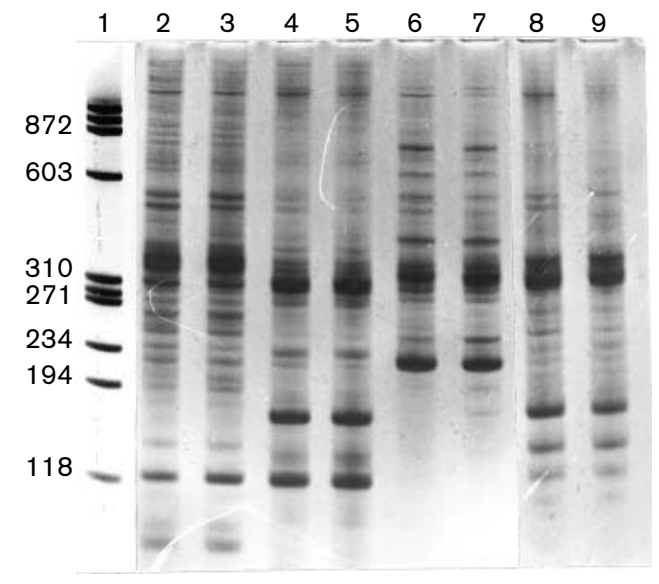

Fig. 1. LSSP-PCR profiles from different species of Leptospira with primer G2 in duplicate. Lanes: 1, molecular size marker ( $\phi 174 /$ HaellI); 2 and 3 , L. interrogans serovar canicola; 4 and 5, L. borgpetersenii serovar castellonis; 6 and 7, L. biflexa serovar andamana; 8 and 9, L. weilii serovar celledoni. Reaction products were separated on an $8 \%$ $(\mathrm{w} / \mathrm{v})$ polyacrylamide gel and silver-stained, as described in Methods.

signatures obtained by LSSP-PCR for genetic identification of serovars of Leptospira, we analysed serovars belonging to six different genomic species. Fig. 4 shows genetic signatures obtained with primer $\mathrm{G} 1$ for analysis of 15 distinct serovars: three from the species L. borgpetersenii (lanes labelled A), four from $L$. santarosai (B), two from $L$. weilii (C), two from $L$. kirschneri (D), two from L. biflexa (E) and two from L. meyeri (F). The main constitutive fragments of LSSP-PCR profiles are listed in Table 2.

In comparison with the signatures obtained with primer G1 with L. interrogans serovars (Fig. 2), all LSSP-PCR profiles obtained for the six different genomic species analysed (Fig.
4) were distinct from those obtained for L. interrogans, except for the LSSP-PCR profile obtained for the serovar grippotyphosa from L. kirschneri, which showed two fragments identical in size ( 180 and $270 \mathrm{bp}$ ) to those observed for the profiles of serovars from L. interrogans with primer G1 (Fig. 2, lanes 1-21; Fig. 4, lane 12). In general, all genomic species analysed with primer G1 displayed fragments that produced distinct genetic signatures for each group of analysed species, the similarity of which made it possible to assign the serovars within to a specific group (Fig. 4).

Specific genetic signatures were also obtained with primer G2 (Fig. 5) for serovars belonging to the same genomic species of Leptospira. LSSP-PCR profiles generated by primer G2 were mainly composed of fragments ranging from approximately 100 to $1400 \mathrm{bp}$. The major bands of the LSSP-PCR patterns are shown in Table 2.

Although the LSSP-PCR profiles obtained with primer G2 were more informative than those obtained with the same samples using primer G1, smaller differences were observed among serovars from different genomic species (Fig. 4). Nevertheless, specific fragments could be observed in profiles of serovars belonging to the same genomic species and therefore permit their identification within the reference group, especially in the genomic species $L$. borgpetersenii (Fig. 5, lanes labelled A), L. santarosai (B) and L. biflexa (E).

In general, genomic signatures obtained with primers G1 and G2 (Figs 4 and 5; Table 2) showed that serovars belonging to the same genomic species produced similar LSSP-PCR profiles, suggesting limited intra-specific polymorphism in the amplified genomic fragments, with more homogeneous profiles obtained for the genomic species L. interrogans (Figs 2 and 3; Table 2).

The stability and reproducibility of genetic signatures of Leptospira were confirmed by experiments in which we tested

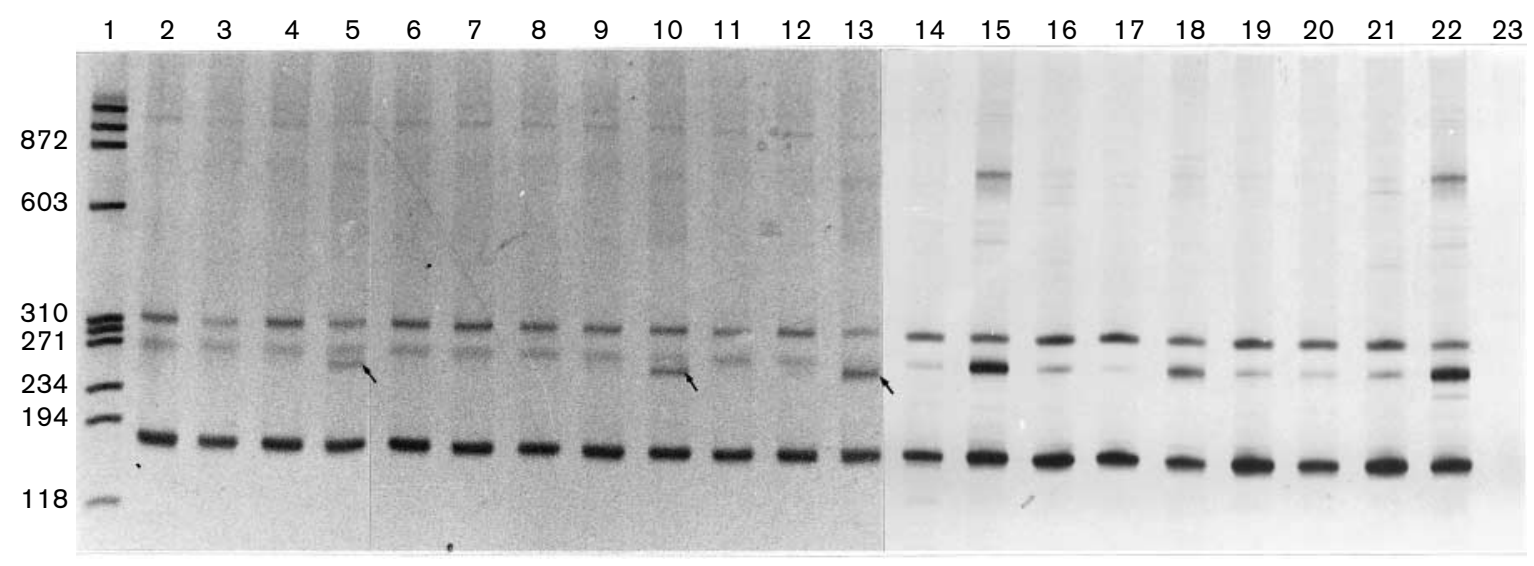

Fig. 2. LSSP-PCR profiles of $L$. interrogans serovars with primer G1. Lanes: 1, molecular size marker ( $\phi 174 /$ HaellI); 2-22, L. interrogans serovars australis (lane 2), autumnalis (3), bataviae (strain Van Tienen) (4), canicola (5), sentot (6), copenhageni (strain M20) (7), icterohaemorrhagiae (8), naam (9), pomona (10), pyrogenes (11), hardjo (12), hebdomadis (13), lai (14), bataviae (strain Swart) (15), lora (16), jalna (17), bangkok (18), muenchen (19), copenhageni (strain Wijnberg) (20), sumneri (21) and shueffneri (22); 23, LSSP-PCR negative control. 
Table 2. Molecular sizes of DNA fragments obtained by LSSP-PCR with G1 and G2 primers

Sizes of main fragments observed with each primer are given in bp. ND, Not determined.

\begin{tabular}{|c|c|c|}
\hline Serovar(s) & G1 & G2 \\
\hline \multicolumn{3}{|l|}{ L. interrogans } \\
\hline $\begin{array}{l}\text { australis, autumnalis, bataviae (strain Van Tienen), sentot, copenhageni (strain M20), } \\
\text { icterohaemorrhagiae, naam, pyrogenes, hardjo, lai, }\end{array}$ & $180,270,310$ & $\begin{array}{l}110,250,280,400 \\
500,600\end{array}$ \\
\hline $\begin{array}{l}\text { bataviae (strain Swart), lora, jalna, bangkok, muenchen, copenhageni (strain Wijnberg), sumneri, } \\
\text { shueffneri }\end{array}$ & $180,270,310$ & ND \\
\hline L. borgpetersenii serovars castellonis, javanica, ballum & $190,267,400,872$ & $100,150,267,275$ \\
\hline \multicolumn{3}{|l|}{ L. santarosai } \\
\hline shermani, weaveri & 185,267 & $150,195,275$ \\
\hline princestown, georgia & 185,267 & ND \\
\hline L. weilii serovars celledoni, coxi & $185,234,267,400$ & $150,200,275,300$ \\
\hline L. biflexa serovars andamana, patoc & $180,234,267,500$ & $\begin{array}{c}200,250,275,300 \\
350\end{array}$ \\
\hline L. meyeri serovars ranarum, semaranga & $185,234,267,310$ & $\mathrm{ND}$ \\
\hline
\end{tabular}

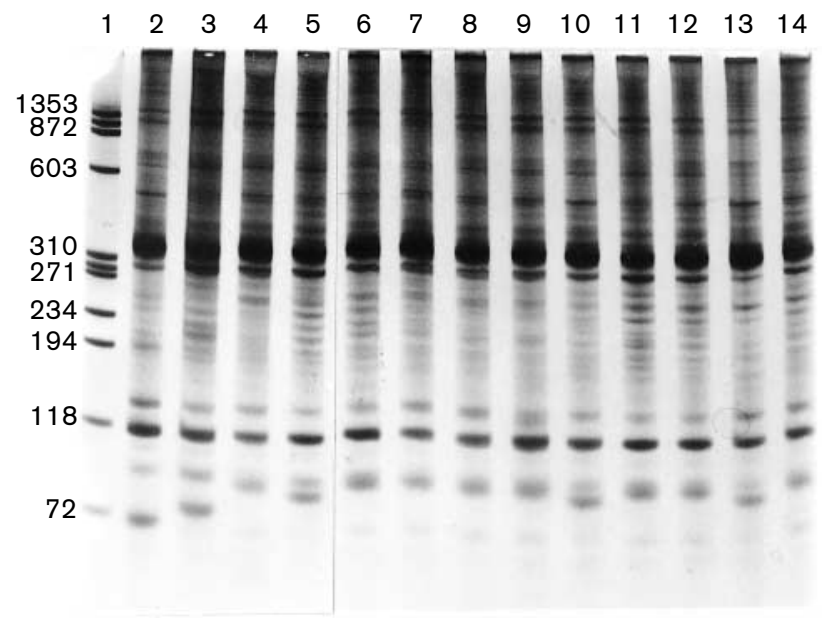

Fig. 3. LSSP-PCR profiles of $L$. interrogans with primer G2. Lanes: 1 , molecular size marker ( $\phi 174 /$ HaellI); $2-14$, L. interrogans serovars australis (2), autumnalis (3), bataviae (strain Van Tienen) (4), canicola (5), sentot (6), copenhageni (strain M20) (7), icterohaemorrhagiae (8), naam (9), pomona (10), pyrogenes (11), hardjo (12), hebdomadis (13) and lai (14).

different amounts of DNA template ( 1 and $2 \mathrm{ng}$ ) with five distinct serovars from four species of the genus Leptospira, $L$. interrogans, L. borgpetersenii, L. biflexa and L. kirschneri. Identical LSSP-PCR profiles were obtained with primer G2 for each of the serovars analysed, even when distinct concentrations of DNA template were used (data not shown).
A comparison among genetic signatures obtained with primer G2 in separate experiments for L. interrogans serovars canicola (Fig. 1, lanes 2 and 3), australis and naam (data not shown) with other serovars belonging to this genomic species (Fig. 3, lanes 2-14) indicated a strong similarity between the profiles and reinforces the usefulness of genetic signatures obtained by LSSP-PCR for the identification of serovars belonging to the same genomic species of Leptospira.

In the same way, serovars castellonis (Fig. 1, lanes 4 and 5) and javanica (data not shown), belonging to the genomic species L. borgpetersenii, presented identical genetic signatures even when experiments were carried out separately and thus allowed the classification of the two serovars to the same group. Identical LSSP-PCR profiles were also obtained for serovars andamana (Fig. 1, lanes 6 and 7) and patoc (data not shown), both belonging to the genomic species L. biflexa.

\section{DNA sequencing}

In this study, we have undertaken the sequence analysis of genomic fragments amplified with primers G1 and G2 originated from genomic DNA of eight serovars belonging to four genomic species of Leptospira: L. interrogans (serovars icterohaemorrhagiae, australis and hardjo), L. borgpetersenii (serovars hardjobovis and ballum), L. weilii (serovars celledoni and coxi) and L. meyeri (serovar ranarum).

All sequenced fragments originating from different serovars were of the same size ( $285 \mathrm{bp})$. An alignment of the sequences obtained is available as supplementary material in JMM Online (http://jmm.sgmjournals.org/). Sequence analysis indicated the presence of three nucleotide alterations, at 


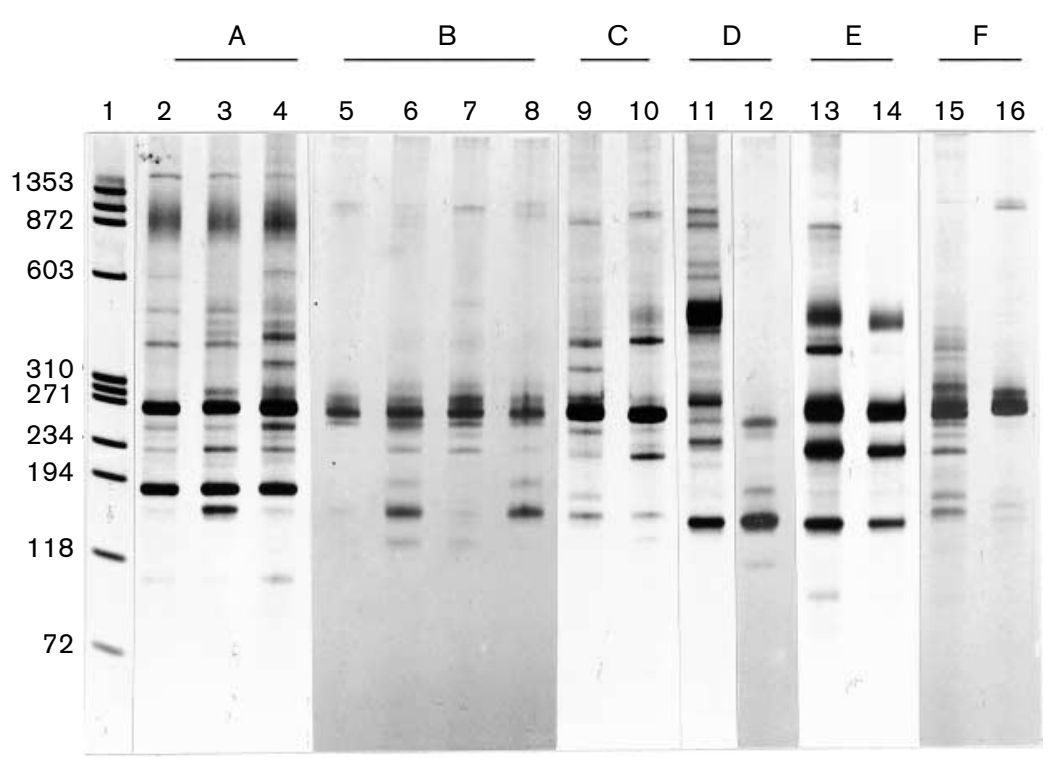

Fig. 4. LSSP-PCR profiles from different species of Leptospira obtained using primer G1. Lanes: 1, molecular size marker ( $\phi 174 /$ Haell $) ;$ 2-4, L. borgpetersenii serovars castellonis (2), javanica (3) and ballum (4); 5-8: L. santarosai serovars shermani (5), weaveri (6), princestown (7) and georgia (8); 9 and 10, L. weilii serovars celledoni (9) and coxi (10); 11 and 12, L. kirschneri serovars ndahambukuje (11) and grippotyphosa (12); 13 and 14, L. biflexa serovars andamana (13) and patoc (14); 15 and 16, L. meyeri serovars ranarum (15) and semaranga (16).

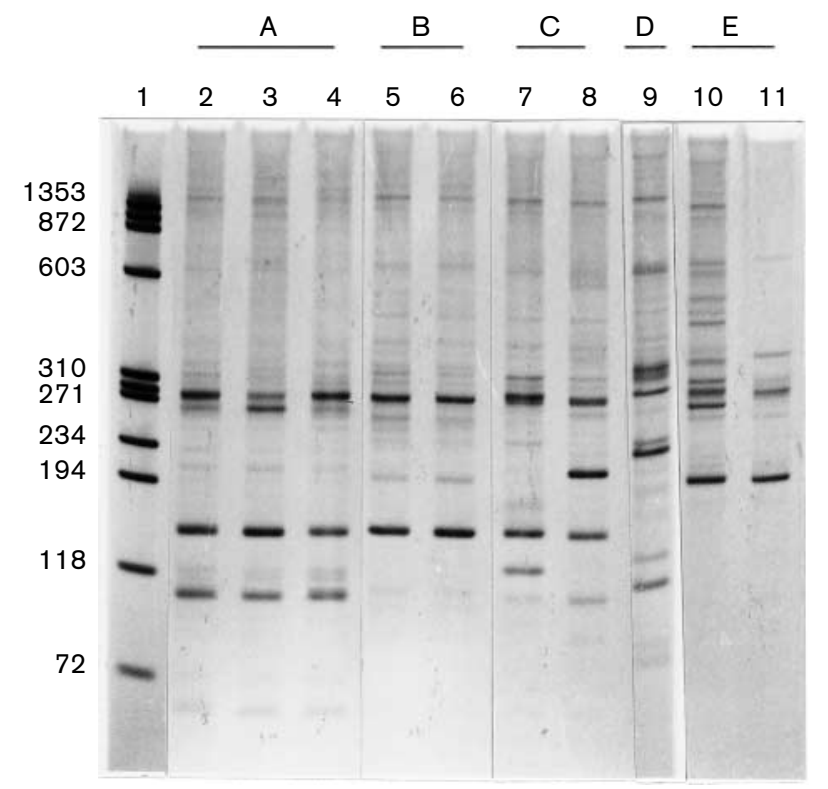

Fig. 5. LSSP-PCR profiles from different species of Leptospira obtained using primer G2. Lanes: 1, molecular size marker ( $\phi 174$ / HaellI); 2-4, L. borgpetersenii serovars castellonis (2), javanica (3) and ballum (4); 5 and 6, L. santarosai serovars shermani (5) and weaveri (6); 7 and 8, L. weilii serovars celledoni (7) and coxi (8); 9, L. kirschneri serovar ndahambukuje; 10 and 11, L. biflexa serovars andamana (10) and patoc (11).

positions 25, 90 and 217, between the serovars icterohaemorrhagiae, australis and hardjo, belonging to the genomic species L. interrogans; nine alterations, at positions 28,31 , 33, 34, 73, 100, 193, 217 and 220, between the serovars hardjobovis and ballum belonging to the species L. borgpetersenii and three nucleotide changes, at positions 139, 220 and 241, in the serovars celledoni and coxi, belonging to the genomic species $L$. weilii. The species $L$. meyeri was repre- sented by a single serovar (ranarum) whose sequence, in comparison with that of $L$. interrogans serovar icterohaemorrhagiae (consensus), demonstrated the presence of 35 nucleotide substitutions, followed by L. borgpetersenii, with 43 changes, and L. weilii, with 50 changes.

Data obtained from the DNA sequence analysis indicated that there is greater variation in the sequence of amplified fragments obtained with primers G1 and G2 among different species and less variation in the sequence of these fragments within the same genomic species.

\section{DISCUSSION}

In the present study, we have undertaken the identification of 35 serovars belonging to seven genomic species of Leptospira through the analysis of a genomic fragment of $285 \mathrm{bp}$ previously amplified by PCR. There was no cross-reaction of primers G1 and G2 with other micro-organisms or human DNA (Gravekamp et al., 1991).

All serovars used in this study were submitted to LSSP-PCR using primer G1 or G2, both of which were capable of producing genetic signatures composed of multiple fragments. The profiles obtained with the primer G2 were more informative (Figs 1, 3 and 5).

The exact mechanism by which LSSP-PCR works is not well understood. One possibility is that the production of multiple fragments is related to the specificity of annealing of the primer to its complementary extremity and, with less specificity, to various sites present in the interior of the fragment. This is achieved in the reaction by the use of high concentrations of the single initiator and Taq DNA polymerase, with an extremely low annealing temperature. The extension of the complex initiator-template DNA by the Taq DNA polymerase produces a pattern of fragments of variable sizes, which can be explained through the dynamic reaction between the primer and its sites of annealing (specific or not) 
as well as between the products generated at the beginning of the reaction, which can react as drivers. When the products of LSSP-PCR are analysed by PAGE, a multi-banded profile is produced (genetic signature) that reflects the variations present in the DNA sequence under analysis (Pena et al., 1994; Barreto et al., 1996).

The LSSP-PCR technique is capable of detecting single or multiple variations in fragments of target DNA and has already been applied to the study of genetic diseases (Pena et al., 1994), the analysis of polymorphisms in human mitochondrial DNA (Barreto et al., 1996), the genetic characterization of subtypes of human papillomavirus (Villa et al., 1995) and strains of Entamoeba histolytica (Gomes et al., 1997) and the molecular typing of strains of Trypanosoma cruzi maintained in culture (Vago et al., 1996) or present in tissues of infected animals (Vago et al., 1996; Andrade et al., 1999) and patients with Chagas disease (Vago et al., 2000).

LSSP-PCR has been also used to analyse reference strains of L. interrogans (Bao et al., 1997). Similar patterns were obtained in eight serovars analysed, but seven other serovars displayed different LSSP-PCR profiles (Bao et al., 1997).

It should be noted that Gravekamp et al. (1993) described the G1/G2-based amplification of DNA fragments of the correct size from six pathogenic species, including $L$. meyeri. This species consists of a pathogenic strain, Iowa City Frog ${ }^{\mathrm{T}}$ $\left(\mathrm{ICF}^{\mathrm{T}}\right)$, from which a PCR product of the correct size was generated, and a non-pathogenic strain, Veltrat Semarang 173 , with the generation of an anomalous PCR product. No G1/G2 amplification was observed from the DNA of strains belonging to the pathogenic species L. kirschneri and the nonpathogenic species $L$. biflexa. We found, however, that application of PCR with relatively large quantities of DNA from strains of the three species L. kirschneri, L. biflexa and L. meyeri resulted in the amplification of a product of the correct size in six of these strains, which were used as templates in the LSSP-PCR.

All sequenced fragments originating from different serovars were identical in size $(285 \mathrm{bp})$, indicating that the apparent differences in the electrophoretic mobility of these fragments that had been observed previously (Oliveira et al., 1995) were not related to differences in their size, but possibly to changes in the structure of the DNA due to nucleotide substitutions. These alterations could be generated either by a few nucleotide substitutions, as observed between serovars from the same species, or by many nucleotide substitutions, as observed between DNA fragments of serovars from different genomic species.

Genetic signatures obtained by LSSP-PCR analysis of products pre-amplified by PCR, using either primer G1 or primer G2, consisted of fragments of approximately 100 to $700 \mathrm{bp}$, with some products consequently larger than the $285 \mathrm{bp}$ used as template. This results from a characteristic of the LSSP-PCR, where it is assumed that the initial products generated in the reaction can act as primers in the subsequent cycles of amplification (Pena et al., 1994; Barreto et al., 1996).
Different genetic signatures were obtained both with the primer $\mathrm{G} 1$ as well as with primer $\mathrm{G} 2$ in the analysis of serovars obtained from different genomic species of Leptospira. However, when the LSSP-PCR profiles generated from serovars belonging to the same genomic species were compared, a clear similarity was apparent, confirming the conservation of the sequence of nucleotides of fragments flanked by the primers G1 and G2.

In agreement with the observations described above, very similar signatures were obtained with primers G1 and G2 for all serovars representing the species L. interrogans. Although the sequence data obtained from the $285 \mathrm{bp}$ fragments of three serovars (icterohaemorrhagiae, australis and hardjo) of L. interrogans indicated the presence of three nucleotide alterations in these fragments, identical LSSP-PCR profiles were obtained for the three serovars with primer G1 as well as with primer G2. One of the possible explanations for this is the location of these mutations in regions distant from the annealing sites of the primers within the fragment analysed.

A large number of serovars of Leptospira have already been described and classified. However, our study was restricted to a small number of serovars representative of the different genomic species, except for the serovars of $L$. interrogans. In this study, the genetic signatures obtained by LSSP-PCR analysis of these serovars presented a satisfactory degree of homogeneity and were sufficient for the characterization and assignment of these serovars to their corresponding genomic species. The characterization of an infective serovar presents an important epidemiological tool for the identification of potential sources of exposure during an outbreak of disease. It will be important to analyse a larger number of serovars representative of diverse genomic species of the genus Leptospira.

The LSSP-PCR technique utilized here permits the assignment of the serovars studied into genomic species according to a new proposal of taxonomical classification of the genus Leptospira, which is based on intra-specific studies of homogeneity and determination of the $\mathrm{G}+\mathrm{C}$ contents of genomic DNA (Yasuda et al., 1987). The similarity and consistency of genomic signatures obtained in this study for serovars belonging to the genomic species $L$. interrogans are in total agreement with the results obtained by Yasuda et al. (1987), who found 96-99\% homogeneity of DNA for representatives of this genomic species.

LSSP-PCR profiles obtained for the serovars ndahambukuge and grippotyphosa, both belonging to the genomic species $L$. kirschneri, showed marked differences, which could be due to the presence of little identity in the sequence of the $285 \mathrm{bp}$ genomic fragments used as templates. Our results are in agreement with other studies (Yasuda et al., 1987), which first classified the serovar grippotyphosa within the genomic species $L$. interrogans, by demonstrating the existence of $100 \%$ homogeneity at the level of DNA between the serovars grippotyphosa and copenhageni (L. interrogans). In our study, high similarity was observed between the genetic signatures obtained for the serovar grippotyphosa (L. kirschneri) and for 
all serovars of the genomic species L. interrogans, including strains M20 and Wijnberg belonging to the serovar copenhageni.

Among five non-pathogenic serovars submitted to analysis of homogeneity of DNA (Yasuda et al., 1987), four were analysed in the present study. The serovars andamana and patoc, belonging to the genomic species L. biflexa, presented very similar LSSP-PCR profiles but were distinct from those obtained for the serovars semaranga and ranarum, which were previously classified within the species $L$. biflexa, but which have been recently reclassified within the genomic species $L$. meyeri, in accordance with differences observed in the $\mathrm{G}+\mathrm{C}$ content of the DNA. However, according to our results, the serovars semaranga and ranarum should be classified as belonging to the genomic species L. biflexa.

The reproducibility and stability of genetic signatures produced by the LSSP-PCR technique were verified in experiments undertaken on separate days and by using different concentrations of template DNA. Identical signatures were obtained for serovars canicola, australis and naam, all of which belong to L. interrogans, which would have permitted the classification of those serovars within the species $L$. interrogans, through the comparison of the profiles with those obtained from other representatives of the group.

Due to their speed and sensitivity, several molecular techniques including the use of serovar-specific probes in DNA hybridization experiments (Yasuda et al., 1987; Terpstra et al., 1986; Zuener \& Bolin, 1990), RFLP analysis (Marshall et al., 1984; Ellis et al., 1988) and ribotyping of 16S rRNA (Merien et al., 1992; Ralph et al., 1993; Perolat et al., 1994) have been used in phylogenetic studies and in the identification of strains and serovars of Leptospira. Although they are very useful for the genetic identification of serovars of Leptospira, many of these techniques present limitations such as being restricted to specific radioactively labelled probes, in addition to the use of complex technical procedures.

Techniques based on the PCR include LS-PCR (low-stringency PCR; Caballero et al., 1994a, b; Brown \& Levett, 1997), AP-PCR (arbitrarily primed PCR; Ralph et al., 1993; Perolat et al., 1994) and RAPD (random amplified polymorphic DNA fingerprinting; Corney et al., 1993; Gerritsen et al., 1995). These techniques offer far more precise identification than the LSSP-PCR technique described here. It should be emphasized, however, that AP-PCR, RAPD and LS-PCR can only be applied once the infecting organism has been isolated and cultured and significant quantities of purified DNA have been obtained. In this respect, the value of LSSP-PCR resides in its immediate possibility of application once the specific PCR amplification of a fragment with diagnostic primers G1/ $\mathrm{G} 2$ has been achieved, even from biological samples.

Furthermore, for those species where the G1/G2 fragment exhibits extensive sequence variability and results in significantly altered LSSP-PCR profiles, this technique also permits serovar identification and thus a rapid means of assessing potential sources of exposure during outbreaks without the need for DNA probes, restriction analysis or DNA sequencing.

In this work, we have demonstrated the application of LSSPPCR in the characterization of diverse serovars of the genus Leptospira through the analysis of polymorphisms present in a genomic fragment of $285 \mathrm{bp}$. Due to the simplicity of its execution, its speed and its capacity to produce highly reproducible and informative genetic signatures, we recommend the use of LSSP-PCR for the identification of Leptospira and as a valuable tool for the molecular epidemiological study of leptospirosis.

\section{REFERENCES}

Andrade, L. O., Machado, C. R., Chiari, E., Pena, S. D. \& Macedo, A. M. (1999). Differential tissue distribution of diverse clones of Trypanosoma cruzi in infected mice. Mol Biochem Parasitol 100, 163-172.

Bao, L., Xiong, Q., Zhang, M., Wu, W., Wan, B., Li, S., Terpstra, W. J. \& Hartskeerl, R. (1997). Characterization of reference strains of $L$. interrogans in China by ISSP-PCR. Hua Hsi I Ko Hsueh Pao 28, 117-121.

Barreto, G., Vago, A. R., Ginther, C., Simpson, A. J. G. \& Pena, S. D. J. (1996). Mitochondrial D-loop "signatures" produced by low-stringency single specific primer PCR constitute a simple comparative human identity test. Am J Hum Genet 58, 609-616.

Brown, P. D. \& Levett, P. N. (1997). Differentiation of Leptospira species and serovars by PCR-restriction endonuclease analysis, arbitrarily primed PCR and low-stringency PCR. J Med Microbiol 46, 173-181.

Caballero, O. L. S., Dias Neto, E., Koury, M. C., Romanha, A. J. \& Simpson, A. J. G. (1994a). Low-stringency PCR with diagnostically useful primers for identification of Leptospira serovars. J Clin Microbiol 32, 1369-1372.

Caballero, O. L. S., Dias Neto, E., Koury, M. C., Romanha, A. J. \& Simpson, A. J. G. (1994b). Low-stringency PCR provides an internal control for negative results in PCR-based diagnosis. PCR Methods Appl 3, 305-307.

Corney, B. G., Colley, J., Djordjevic, S. P., Whittington, R. \& Graham, G. C. (1993). Rapid identification of some Leptospira isolates from cattle by random amplified polymorphic DNA fingerprinting. J Clin Microbiol 31, 2927-2932.

Ellis, W. A., Thiermann, A. B., Montgomery, J., Handsaker, A., Winter, P. J. \& Marshall, R. B. (1988). Restriction endonuclease analysis of Leptospira interrogans serovar hardjo isolates from cattle. Res Vet Sci 44, 375-379.

Gerritsen, M. A., Smits, M. A. \& Olyhoek, T. (1995). Random amplified polymorphic DNA fingerprinting for rapid identification of leptospiras of serogroup Sejroe. J Med Microbiol 42, 336-339.

Gomes, M. A., Silva, E. F., Macedo, A. M., Vago, A. R. \& Melo, M. N. (1997). LSSP-PCR for characterization of strains of Entamoeba histolytica isolated in Brazil. Parasitology 114, 517-520.

Gravekamp, C., Van de Kemp, H., Carrington, D., Van Eys, G. J. J. M., Everard, C. O. R. \& Terpstra, W. J. (1991). Detection of leptospiral DNA by PCR in serum from patients with copenhageni infection. In Proceedings of the Leptospirosis Research Conference, pp. 151-164. Edited by Y. Kobayashi. Tokyo.

Gravekamp, C., Van de Kemp, H., Franzen, M., Carrington, D., Schoone, G. J., Van Eys, G. J. J. M., Everard, C. O. R., Hartskeerl, R. A. \& Terpstra, W. J. (1993). Detection of seven species of pathogenic leptospires by PCR using two sets of primers. J Gen Microbiol 139, $1691-1700$. 
Johnson, R. C. \& Harris, V. G. (1967). Differentiation of pathogenic and saprophytic leptospires. I. Growth at low temperatures. J Bacteriol 94, $27-31$.

Marshall, R. B., Winter, P. J. \& Yanagawa, R. (1984). Restriction endonuclease DNA analysis of Leptospira interrogans serovars icterohaemorrhagiae and hebdomadis. J Clin Microbiol 20, 808-810.

Merien, F., Amouriaux, P., Perolat, P., Baranton, G. \& Saint Girons, I. (1992). Polymerase chain reaction for detection of Leptospira spp. in clinical samples. J Clin Microbiol 30, 2219-2224.

Oliveira, M. A. A., Hartskeerl, R., Caballero, O. L. S. D. \& 8 other authors (1994). LSSP-PCR: a methodology for Leptospira species determination using gene fragments derived during PCR based diagnosis. In Annals of the VIIIth Meeting of European Leptospira Workers, vol. 1, pp. 53-55. Anzio, Rome.

Oliveira, M. A. A., Caballero, O. L. S. D., Dias Neto, E., Koury, M. C., Romanha, A. J., Carvalho, J., Hartskeerl, R. A. \& Simpson, A. J. G. (1995). Use of nondenaturing silver-stained polyacrylamide gel analysis of polymerase chain reaction amplification products for the differential diagnosis of Leptospira interrogans infection. Diagn Microbiol Infect Dis 22, 343-348.

Pena, S. D. J., Barreto, G., Vago, A. R., De Marco, L., Reinach, F. C., Dias Neto, E. \& Simpson, A. J. G. (1994). Sequence-specific 'gene signatures' can be obtained by PCR with single specific primers at low stringency. Proc Natl Acad Sci U S A 91, 1946-1949.

Perolat, P., Merien, F., Ellis, W. A. \& Baranton, G. (1994). Characterization of Leptospira isolates from serovar hardjo by ribotyping, arbitrarily primed PCR, and mapped restriction site polymorphisms. J Clin Microbiol 32, 1949-1957.

Ralph, D., McClelland, M., Welsh, J., Baranton, G. \& Perolat, P. (1993).
Leptospira species categorized by arbitrarily primed polymerase chain reaction (PCR) and by mapped restriction polymorphisms in PCRamplified rRNA genes. J Bacteriol 175, 973-981.

Sanguinetti, C. J., Dias Neto, E. \& Simpson, A. J. G. (1994). Rapid silver staining and recovery of PCR products separated on polyacrylamide gels. Biotechniques 17, 914-921.

Tamai, T., Sada, E. \& Kobayashi, Y. (1988). Restriction endonuclease DNA analysis of Leptospira interrogans serovars Icterohaemorrhagiae and Copenhageni. Microbiol Immunol 32, 887-894.

Terpstra, W. J., Schoone, G. J. \& ter Schegget, J. (1986). Detection of leptospiral DNA by nucleic acid hybridization with ${ }^{32} \mathrm{P}$ - and biotinlabelled probes. J Med Microbiol 22, 23-28.

Vago, A. R., Macedo, A. M., Oliveira, R. P. \& 8 other authors (1996). Kinetoplast DNA signatures of Trypanosoma cruzi strains obtained directly from infected tissues. Am J Pathol 149, 2153-2159.

Vago, A. R., Andrade, L. O., Leite, A. A. \& 7 other authors (2000). Genetic characterization of Trypanosoma cruzi directly from tissues of patients with chronic Chagas disease: differential distribution of genetic types into diverse organs. Am J Pathol 156, 1805-1809.

Villa, L. L., Caballero, O. L., Levi, J. E., Pena, S. D. J. \& Simpson, A. J. G. (1995). An approach to human papillomavirus identification using low stringency single specific primer PCR. Mol Cell Probes 9, 45-48.

Yasuda, P. H., Steigerwalt, A. G., Sulzer, K. R., Kaufman, A. F., Rogers, F. \& Brenner, D. J. (1987). Deoxyribonucleic acid relatedness between serogroups and serovars in the family Leptospiraceae with proposals for seven new Leptospira species. Int J Syst Bacteriol 37, 407-415.

Zuener, R. L. \& Bolin, C. A. (1990). Nucleic acid probe characterizes Leptospira interrogans serovars by restriction fragment length polymorphisms. Vet Microbiol 24, 355-366. 